\title{
An experimental investigation of the 'tenuous trade-off' between risk and incentives in organizations
}

\author{
Subhasish M. Chowdhury ${ }^{1}$ (D) Alexandros Karakostas ${ }^{2}$
}

Published online: 18 June 2019

(C) The Author(s) 2019

\begin{abstract}
We investigate experimentally the relationship between risk and incentives in a principal-agent setting. In contrast to the existing empirical literature that describes such relationship as 'tenuous' or inconclusive, we find a clear negative relationship — supporting the prediction of the standard theoretical model. Specifically, we find that principals reduce the size of the offered piece rates with an increase in risk and instead provide positive fixed wages. Furthermore, we find no relationship between the variance in the performance and the effort choice of the agent, and a strong positive relationship between the effort choice of the agents and the offered piece rates as well as fixed wage, suggesting positive reciprocity. Finally, we find evidence of social projection by the principals regarding the agents' degree of risk aversion.
\end{abstract}

Keywords Moral hazard $\cdot$ Hidden action $\cdot$ Risk $\cdot$ Incentives

\section{Introduction}

One of the most celebrated results in personnel and organizational economics is on the optimal incentive intensity of employment contracts (Holmstrom and Milgrom 1987). A key tenet of this study is that in markets, where employees' efforts are unobservable and outputs are subject to high volatility due to idiosyncratic market factors, the use of performance measures that are tied to outputs should be less common than in markets exhibiting less volatility and more stable performance. This

\footnotetext{
We thank Chris Starmer (the editor), two anonymous referees, Brice Corgnet, Daniel Zizzo, the seminar participants at the University of East Anglia, and the participants at the 2018 FUR the University of East Anglia for financial support. Any remaining errors are our own.

Subhasish M. Chowdhury

s.m.chowdhury@bath.ac.uk

1 Department of Economics, University of Bath, Bath BA2 7AY, UK

2 School of Economics, University of Queensland, Brisbane 4067, Australia
} Conference for useful comments, and the Centre for Behavioural and Experimental Social Science at 
is because, as agents are risk averse, they will be less willing to accept contracts that tie their earnings to stochastic factors beyond their control. Consequently, the greater the risk associated with the environment, the lower the incentive intensity or performance pay of the employment contract. In the literature, this is often termed as the Incentive Intensity Principle (Milgrom and Roberts 1992).

Despite the clear intuition of the model, the empirical evidence on the relationship between riskiness in the environment and the incentive intensity of payment schemes has been rather mixed, casting doubts on the validity of the model (Prendergast 1999, 2000, 2002) reports the findings from 26 empirical studies, out of which only four find evidence for a negative relationship, as predicted in the theory. This dearth of empirical support has led to the proliferation of new theoretical models that attempt to explain why a negative relationship may not be observed in the field. For instance, Prendergast (2002) argues that the delegation of principal's authority to an agent can explain the evidence for a positive relationship between incentive intensity and performance measure. Similarly, Budde and Kräkel (2011) show that combining risk aversion to limited liability could account for such a positive relationship. Likewise, Wright (2004) demonstrates that when one accounts for heterogeneous managers differing in their degrees of risk aversion, both negative and positive relationships are plausible.

In this paper, we present a controlled laboratory experiment that tests the relationship between incentive intensity and risk while isolating any alternative explanations. Testing this relationship in the lab has two significant advantages: first, it provides enhanced control, which allows implementing precise values of the parameters of the model (Charness and Kuhn 2010; Camerer and Weber 2013); second, it allows ruling out alternative explanations (such as the ones discussed earlier) of why the relationship observed using field data is weak or non-existent (Charness and Kuhn 2010; Corgnet and Hernán-González 2018).

To the best of our knowledge, this is only the second experimental study that tests the relationship between incentive intensity and risk. Very recently, Corgnet and Hernán-González (2018), henceforth C-HG, report an experiment that independently tests the trade-off between risk and incentives. Our experimental design shares various similarities and some crucial divergences with that of C-HG. Similar to them, we conduct between-subject treatments, in which output is either deterministic (baseline treatment) or stochastic (risk treatments). In one of our risk treatments, as in C-HG, we insure the principal towards the stochastic element to ensure his risk neutrality. However, as a robustness test, we additionally conduct another risk treatment, where the principal is not insured towards risk, allowing for both the principal and the agent to be risk averse. Furthermore, like C-HG, we have collected data on risk aversion for both principals and agents using the Holt and Laury (2002) task. However, whereas C-HG elicits the beliefs of principals on agents' risk aversion, we rely on social projection (Robbins and Krueger 2005). The key difference between our designs and that of C-HGs, however, is the way the agents exert effort in a principal-agent setting. In both the studies, the principal offers a linear contract to the agent that consists of a fixed wage and a share on agent's production. However, whereas C-HG employs a real-effort summation task to simulate the agent's effort choice, we follow the tradition in the gift exchange literature (Fehr et al. 1998; 
Anderhub et al. 2002; Fehr and Gächter 2002; Fehr and Schmidt 2004; Fehr et al. 2007) in which the agent states/chooses an effort level subject to a (convex) cost of effort function.

As with every design choice, there are certain advantages and disadvantages of using a stated-effort vs. a real-effort task. ${ }^{1}$ A real-effort task is a more intuitive approach closer to the field. However, an underpinning assumption of the Incentive Intensity Principle (henceforth IIP) is that principals (and agents) are aware of the precise cost of the effort function that the agent is subjected to. Using a real-effort task introduces heterogeneity in the cost of effort and requires the principal to rely on his beliefs regarding the agent's ability to complete the task. In essence, introducing a real-effort task transforms the moral hazard problem into a combined problem of moral hazard and adverse selection. As shown in C-HG, this may not affect the direction of the predictions of the IIP; but it complicates the analysis of the contract of the principal. In addition, in the presence of asymmetric information regarding the agent's ability, the principal's optimal contract does not implement the efficient level of effort even in the absence of noise. In addition, also noted by C-HG, it could be argued that the baseline treatment is not strictly deterministic, since the agents may find the solution to the task by luck, and/or the agents may not know their ability of the task with certainty. Using a stated-effort rather than a real-effort task eliminates these informational issues and brings the experiment closer to theory, though it does not come without limitations. As shown in Charness et al. (2004), stated effort in gift exchange games is sensitive to the way that payoffs are presented to the subjects. In particular, they show that providing a payoff table reduces average wages by $19 \%$ and discretionary effort by $69 \%$. Even though we do not provide agents with an explicit payoff table, we provided calculators that allowed estimating the potential profits for given effort levels and stochastic random factor outcomes. Nevertheless, since we are interested in treatment effects, we expect such issues not to affect our results.

According to the linear agency model, the optimal effort choice of the agent depends on the marginal cost of effort and is unrelated to the noise in the performance measure. Sloof and van Praag (2008) test this experimentally and compare their results with expectancy theory, a theory developed by psychologists that predicts a negative relationship between effort and noise in the performance measure. In contrast to the current study that focuses on the optimal choice of incentive intensity, Sloof and van Praag (2008) focus on the optimal effort choice in a real-effort (number adding) task with noise. Due to their divergent aim and to reduce complexity, they abstract away from the role of a principal and the subjects had to allocate effort between two different tasks. Their findings are in line with the linear agency model, as their results suggest that effort levels are invariant to the distribution of noise terms.

Overall, our results are broadly in support of the theoretical predictions of the IIP. We find a negative relationship between incentive intensity and risk, in line with

\footnotetext{
1 See Charness et al. (2018) for a recent discussion on the advantages and disadvantages of the two approaches.
} 
theoretical predictions and the findings of C-HG. The principals, on average, offer lower piece rates and higher fixed wages in the risk treatments than in the no risk treatment. However, in contrast to both C-HG and Sloof and van Praag $(2008,2010)$ who observe an increase in effort with higher risk; we find, again in line with the predictions of Hart and Holmström (1986), that agents respond with lower effort levels when the performance measure is noisier. The most plausible explanation for this difference in effort responses could be the fact that we used a stated-effort approach rather than a real-effort task. Finally, in line with C-HG and Sloof and van Praag $(2008,2010)$, we find that the effort choices of the employees are not affected by the volatility in the performance measure in contrast to the expectancy theory of motivation (Vroom 1964).

The remainder of this paper is organized as follows: Sect. 2 presents the theoretical framework under the parametric restrictions in the experiment, and Sect. 3 describes the specifics of the experimental design. Section 4 presents the results and Sect. 5 concludes. The instructions as well as proofs of the theoretical predictions are provided in the "Appendix".

\section{The principal-agent model}

In this section, we construct a principal-agent model following Holmstrom and Milgrom (1987) and describe the theoretical solutions. First, we consider the case, where there is no stochastic variance on output, and therefore, effort is observable (but not contractible). Second, we consider the case, where output is the sum of effort and a stochastic random factor. Here, the principal cannot distinguish which part of the output is due to the agent's effort and which part is due to the stochastic random factor.

With no risk, the revenue $(R)$ depends on the agent's effort level $e$, such that $R(e)=50 e$. The agent starts with an endowment of effort; s/he bears an effort cost of $C(e)=e^{2}$ with $e \in\{5,6, \ldots, 10\}$. The principal also holds an endowment and s/he jointly decides on a fixed wage $F \in\{50,51, \ldots, 200\}$ and a piece rate $\beta \in\{5,6, \ldots, 40\}$ that specifies how much Experimental Currency Units (ECUs) that the agent will receive for each unit of effort. ${ }^{2}$ Hence, the agent's payoff is given by

$$
P^{\mathrm{A}}=F+\beta e-C(e)+\text { endowment. }
$$

Conversely, the principal's payoff is

$$
P^{\mathrm{P}}=R(e)-F-\beta e+\text { endowment. }
$$

Assuming that both principal and the agent are payoff maximizers, the game theoretic solution, derived in "Appendix A" for the specific parameters used in the

\footnotetext{
2 Note that in our model, accepting the contract implied a minimum effort of 5. The compensation an employee received for an effort of 5 was 75 ECU split between a fixed wage of 50 ECU and a piece rate of 5 ECU per unit.
} 
experiment, predicts the principal to offer a piece rate of 20 and a fixed wage of 50 and the agent to exert an effort level of 10. The consequent payoff, after taking into account their endowments, for the principal is $P^{P}=450$ and for the agent is $P^{\mathrm{A}}=350$.

With risk in the environment, the piece rate in output is subject to a stochastic variance $(V)$, which is normally distributed with a mean of zero. When we make the standard assumption that the principal is risk neutral and the agent is risk averse, then the principal faces a trade-off between incentivizing the agent, and providing him with insurance for the variance in payoffs that is created due to the stochastic random factor. Holmstrom and Milgrom (1987) have shown that the optimal incentive intensity (i.e., piece rate) is given by

$$
\beta^{*}=R^{\prime}(e) /\left[1+r V C^{\prime \prime}(e)\right],
$$

where $r$ is the coefficient of absolute risk aversion (ARA) of the agent. Given that $V$ in our experiment was set at 2.5 and the rest of the factors remained unchanged, the optimal $\beta^{*}$ is

$$
\beta^{*}=50 /(1+5 r) \text {. }
$$

We elicited the coefficient of ARA for all subjects using the Holt and Laury (2002) questionnaire. Note that the model assumes that the principal is aware of the exact value of the coefficient of ARA for each agent. Hence, to generate a benchmark, we calculated an average $\bar{r}$ from all subjects in our experiment. The average coefficient of ARA from all subject participants was $\bar{r}=0.549$. After inserting $\bar{r}$ in Eq. 15 in "Appendix A", it yields the optimal $\beta^{*}=13.35$. With optimal incentive intensity determined, it is easy to show that the optimal effort level for the employee is 7, while the optimal fixed wage remains unchanged at 50 ECU. However, as the participants in our subject pool could select only one decimal, the optimal choice for an employer is $\beta^{*}=13.4$. Consequently, the expected profits (including endowments) for the principal and the agent, respectively, are: $P^{\mathrm{P}}=516$ and $P^{\mathrm{A}}=384$.

\section{Experimental design}

The experiment was conducted at the University of East Anglia in Z-Tree (Fischbacher 2007) with 360 student participants of a variety of backgrounds. The experiment employed a fictional currency, ECU, which was converted to Great Britain Pounds at the end of the experiment at the rate of $£ 0.02$ per ECU. Each session lasted approximately $80 \mathrm{~min}$ and the subjects earned on average $£ 9.60$, including a show-up fee of $£ 2.00$.

Each session consisted of ten rounds, and the first three rounds were practice rounds. At the end of the ten rounds, the subjects had to complete the Holt and Laury (2002) risk elicitation questionnaire. After the completion of the questionnaire, the subjects had to complete two non-incentivized psychology questionnaires (Blais and Weber 2006) that measures risk taking and risk perception. As the first three rounds acted as practice rounds, in the end of the experiment, one of the remaining seven rounds was chosen randomly and was paid privately and anonymously to the subjects 
in cash, along with any additional earnings from the Holt and Laury (2002) task. A random matching procedure was implemented at the start of each round to control for reputation effects. A positive frame of employer/employee was adopted instead of an abstract frame, as context can be useful to enhance understanding (Cooper and Kagel $2003,2009)$ in an organizational setting. In addition, both the employer/employee frame (e.g., Fehr et al. 1998; Karakostas et al. 2017) and the buyer/seller frame (e.g., Fehr and Gächter 2002; Fehr et al. 2007) have been previously used in the context of the gift exchange finding no qualitative differences between the frames.

The experiment had three treatments: no risk (NR), risk (R), and both in risk (BR). We ran 30 sessions in total (10 sessions per treatment) with 12 subjects in each session. The subjects were split evenly as employers or employees and maintained the same role throughout the experiment. The instructions were common for both employers and employees. After the subjects had read the instructions, they had to answer control questions to ensure that they properly understood the instructions. If a subject provided a wrong answer in any question, a detailed explanation appeared in his/her computer screen. All three treatments were identical in every aspect apart from how risk affected the profit functions of the employers and employees.

In the NR treatment, the employer had to offer an employment contract to the employee requesting him or her to exert a level of effort. In the employment contract, the employer specified the size of the fixed wage, piece rate and a suggested effort level. The fixed wage could range between 50 and 200, the piece rate between 5 and 40, and the suggested effort level between 5 and $10 .{ }^{3}$ Then, the employee had to decide whether to accept or reject the contract offer. If the contract was rejected, the round finished and both subjects earned only their endowments (200 ECU). If the employee accepted the contract, then s/he had to decide an effort level between 5 and 10. Recall that exerting effort was costly and the cost of effort was given by the function $C(e)=e^{2}$. The total revenue for the employer was given by $\mathrm{TR}=50 e$. After the agent decided an effort level, experimental payoffs were given by

$$
\begin{gathered}
\pi_{\text {Employer }}=\text { Endowment }+50 e-[\text { Fixed wage }+(\text { Piece Rate }) e], \\
\pi_{\text {Employee }}=\text { Endowment }+ \text { Fixed wage }+(\text { Piece Rate }) e-C(e) .
\end{gathered}
$$

In the $\mathrm{R}$ treatment, the profit function of the employee was altered to incorporate the risk associated with the incentive measure (the piece rate). According to the theory, the random factor is assumed to generate noise in the performance measure not allowing the principal to directly observe the effort choice of the agent. ${ }^{4}$ Given that the principal is assumed to be risk neutral and the random factor is assumed to be normally distributed with a mean of zero, s/he will not be

\footnotetext{
3 In order to ensure that no subject made any losses due to the variance of the random factor, we decided that there would be a minimum effort level and consequently a minimum wage-which is prevalent in the field. To avoid creating any potential cues regarding which payment mechanism the employer should use, we split the minimum wage equally between the fixed wage and piece rate.

4 The random factor was presented to the subjects in the form of a table in which each possible value that $x$ could take was assigned a respective probability. The table is included in the instructions in "Appendix B".
} 
Table 1 Theoretical predictions

\begin{tabular}{llll}
\hline & Fixed wage & Piece rate & Effort \\
\hline NR & 50 & 20 & 10 \\
R & 50 & 13.35 & 7 \\
\hline
\end{tabular}

affected by the associated risk in the total revenue or on its impact on the piece rate. The main concern for the principal is whether the risk dilutes the incentives generated by the piece rate for the risk averse agent. Although the principal is assumed to be risk neutral, as s/he is able to diversify the associated risk; given that $\mathrm{s} / \mathrm{he}$ is assigned only one agent, this assumption may not be justifiable. To overcome this problem and to ensure the principal can indeed act as risk neutral, the risk component was removed from his or her profit function. Hence, the experimenter acts as an insurer for the principal allowing the principal to act as if s/he was risk neutral. This allows us to rule out any effects from the principal being risk averse, which could deviate from a key assumption of the theoretical model. Therefore, the profit function of the employer was held unchanged, whereas the piece rate that was paid to the agent was formulated by the sum of the effort and the random factor $(x)$ :

$$
\begin{gathered}
\pi_{\text {Employer }}=\text { Endowment }+50 e-[\text { Fixed wage }+(\text { Piece Rate }) e], \\
\pi_{\text {Employee }}=\text { Endowment }+ \text { Fixed wage }+(\text { Piece Rate })(e+x)-C(e) .
\end{gathered}
$$

Finally, although not directly related to our research question, we ran the BR treatment as a robustness check to test whether imposing risk neutrality to the principal in the $\mathrm{R}$ treatment has an effect in his/her behavior. Hence, in this treatment, the profit function of the agent remained the same as in the R treatment, but the principal was also subject to risk:

$$
\begin{gathered}
\pi_{\text {Employer }}=\text { Endowment }+50(e+x)-[\text { Fixed wage }+(\text { Piece Rate })(e+x)], \\
\pi_{\text {Employee }}=\text { Endowment }+ \text { Fixed wage }+(\text { Piece Rate })(e+x)-C(e) .
\end{gathered}
$$

If the imposition of risk neutrality in the $\mathrm{R}$ treatment indeed has no effect on principal behavior, then one would expect (statistically) similar outcomes in the $\mathrm{R}$ and the BR treatment. However, if there is a difference in the outcomes, then the risk neutrality assumption for the principal will turn out to be a crucial one.

Table 1 summarizes the theoretical predictions for the fixed wage, piece rate, and effort for the $\mathrm{R}$ and NR treatments. The model suggests that the optimal piece rate $\beta$ will be 20 in the NR and 13.35 in the R treatment ("Appendix B"), since the employer partially insures the employee. Hence, following the theoretical predictions, we can coin the following hypotheses. 
Table 2 Average fixed wages, piece rates, and efforts across treatments

\begin{tabular}{llll}
\hline & Fixed wage & Piece rate & Effort \\
\hline NR & 69.93 & 16.51 & 7.44 \\
R & 72.75 & 14.41 & 6.94 \\
BR & 78.94 & 15.38 & 7.00 \\
\hline
\end{tabular}

Hypothesis 1 The piece rate is lower in the R treatment than in the NR treatment. In particular, the piece rate offered by the principals in the NR and R treatments are equal to $13.4 \mathrm{ECU}^{5}$ and $20 \mathrm{ECU}$, respectively. ${ }^{6}$

The agent's effort level is expected to depend only on the piece rate offered by the principal (and not on the fixed wage or the noise in the performance measure), as it formulates the incentive constraint of the agent.

Hypothesis 2 Effort level depends solely to the piece rate the principal offers to the agent. The fixed wage level and the noise in the performance measure have no influence on the effort level chosen by the agent.

Note that theoretically the principal is assumed to know the coefficient of ARA of the agent to determine the optimal piece rate in the $\mathrm{R}$ treatment. Although we had examined the possibility of obtaining the coefficient of risk aversion of the agents in advance and provide it to the principals, we believe that this information would be very difficult to be interpreted. Therefore, we relied on the concept of social projection (Orbell and Dawes 1991). According to the social projection theory, each player will project his own characteristics to others and use them as a cue on how they are more likely to behave [see Krueger (2007) for a review]. If we assume that the principal will use social projection to infer how risk averse the agent they are matched with is, then we can formulate the following hypothesis.

Hypothesis 3 The more risk averse the principal is, the more risk averse s/he expects the agent to be; and as a result, the smaller the piece rate that s/he offers to the agent.

\section{Results}

In this section, we first present the descriptive statistics and the results of the session-level two-tailed non-parametric tests on piece rates, fixed wages, and effort levels across the treatments. Then, we continue with regression analyses with respect to the piece rates and effort.

\footnotetext{
5 The precise prediction of the model given our parameterization is 13.35 . However, since only one decimal was allowed the profit maximizing choice for the employee is 13.4.

${ }^{6}$ One should, however, take the quantitative predictions of our model with caution, as it relies on the estimated risk aversion parameter from the whole population. We thank a referee for pointing this out.
} 
Table $3 \mathrm{M}-\mathrm{W}$ tests for fixed wage, piece rate, and effort across treatments

\begin{tabular}{llll}
\hline & Fixed wage & Piece rate & Effort \\
\hline NR vs. R & 0.762 & $0.034^{* *}$ & 0.104 \\
R vs. BR & 0.273 & 0.199 & 0.734 \\
NR vs. BR & 0.131 & 0.325 & 0.161 \\
\hline
\end{tabular}

All tests are two-tailed tests conducted at session level to control for non-independence of observations. The tests reported are for all offers, conducting the tests only on accepted offers leads to qualitatively similar results

\subsection{Descriptive statistics and non-parametric tests}

Table 2 summarizes the mean values of the aforementioned variables. When there is noise in the environment (R), employers offer on average a higher fixed wage and a lower piece rate than when there is no noise (NR). In addition, the effort level is smaller in the R treatment than in the NR treatment (and almost the same as in the BR treatment). ${ }^{7}$

We conducted pairwise Mann-Whitney tests for fixed wages, piece rates, and effort levels across the treatments. Table 3 provides a summary of the $p$ values of these tests. The variable is depicted on the horizontal axis and the treatment comparison on the vertical axis. As can be seen, only the difference between piece rates in the $\mathrm{R}$ and the NR treatments is statistically significant (Mann-Whitney $p=0.034$ ). These are summarized in Result 1.

Result 1 In line with Hypothesis 1, the piece rate is significantly lower in the $\mathrm{R}$ treatment than in the NR treatment.

Interestingly, the average piece rate that was offered by the principals in the $\mathrm{R}$ treatment was significantly larger than the piece rate predicted by the model (Mann-Whitney $p=0.023$ ).

Result 2 In contrast to Hypothesis 1, on average, the piece rate offered in the $\mathrm{R}$ treatment was statistically significantly larger than the predicted piece rate of 13.4.

Note, further, that the piece rates in the BR treatment is in between the piece rate in the R and the NR treatments; and it is not statistically different from either of the two. This can be interpreted, as injecting risk to the principal does not significantly change behavior (BR vs. R).

Table 4 provides a summary of the Spearman correlation tests for fixed wage, effort, and piece rate-for each treatment. By conducting Spearman correlation tests between the three variables above, we found (as expected) a very strong positive correlation between effort and piece rate. In addition, we observe a negative correlation between fixed wage and piece rate, implying that the employers use the two tools as substitutes to each other. Finally, we observe a weak negative correlation between the fixed wage and effort, in line with C-HG and Sloof and van Praag

\footnotetext{
7 Since the acceptance rates were very high in all the treatments $(97.6 \%, 96.6 \%$ and $96.9 \%$ in the NR, R and $\mathrm{BR}$, respectively), we do not provide any further analyses on acceptance rates.
} 
Table 4 Spearman correlation coefficients for fixed wage, piece rate, and effort

\begin{tabular}{|c|c|c|c|c|c|}
\hline \multirow[t]{2}{*}{ All treatments } & \multicolumn{5}{|c|}{ Both risk } \\
\hline & Fixed wage & Piece rate & & Fixed wage & Piece rate \\
\hline Fixed wage & - & - & Fixed wage & - & - \\
\hline Piece rate & $-0.380 * * *$ & - & Piece rate & $-0.352 * * *$ & - \\
\hline Effort & $-0.145^{* * *}$ & $0.721 * * *$ & effort & $-0.126^{* * *}$ & $0.720 * * *$ \\
\hline \multirow[t]{2}{*}{ No risk } & & & & Risk & \\
\hline & Fixed wage & Piece rate & & Fixed wage & Piece rate \\
\hline Fixed wage & - & - & Fixed wage & - & - \\
\hline Piece rate & $-0.473 * * *$ & - & Piece rate & $-0.291 * * *$ & - \\
\hline Effort & $-0.207 * * *$ & $0.730 * * *$ & Effort & $-0.074 * *$ & $0.702 * * *$ \\
\hline
\end{tabular}

Note: $* p<0.1, * * p<0.05, * * * p<0.01, * * * * p<0.001$

(2010). However, as we discuss in the following section, when we control for the impact of piece rates on effort in regression analyses, we observe a weak but positive relationship between effort and fixed wages, ceteris paribus.

Interestingly, we see that even though the correlations between piece rates and effort are quite stable across treatments, this is not true for the correlations for effort and fixed wages, and fixed wages and piece rates. Instead, we observe that employers treat fixed wages and piece rates as much weaker substitutes in NR than in R and BR $(-0.291$ relative to -0.473 and -0.352$)$. This indicates that when the employees where not subject to risk, a piece rate seemed a relatively more attractive alternative to fixed wages.

\subsection{Regression analyses}

In this section, we report the results of panel regressions with random effects with data from all the three treatments at the subject level and error clustering at session level first for the piece rates (Table 5) and then for effort (Table 6). ${ }^{8}$ The regressions employ dummy variables for the experimental treatments, with the NR treatment as baseline. As three different measures of risk, (Holt and Laury (2002), risk taking, and risk perception) were collected, in each regression, only one of them is used at a time. All three different measures of risk have been centered. ${ }^{9}$ In addition, relying on the literature on social projection, we use the $r$ coefficient of the employer instead of the employee, assuming that the employer would expect the employee to be as risk averse (or loving) as s/he is. Furthermore, we used interaction variables between each of the risk elicitation measures and the $\mathrm{R}$ treatment to capture any potential interaction effects between risk attitudes and the R treatment. Finally, we

\footnotetext{
${ }^{8}$ We have also conducted hierarchical linear models and models with pairwise treatment data (e.g., R vs. $\mathrm{NR}$ ), and found qualitatively similar results.

${ }^{9}$ See Dalal and Zickar (2012) for a recent discussion on the advantages of centering.
} 


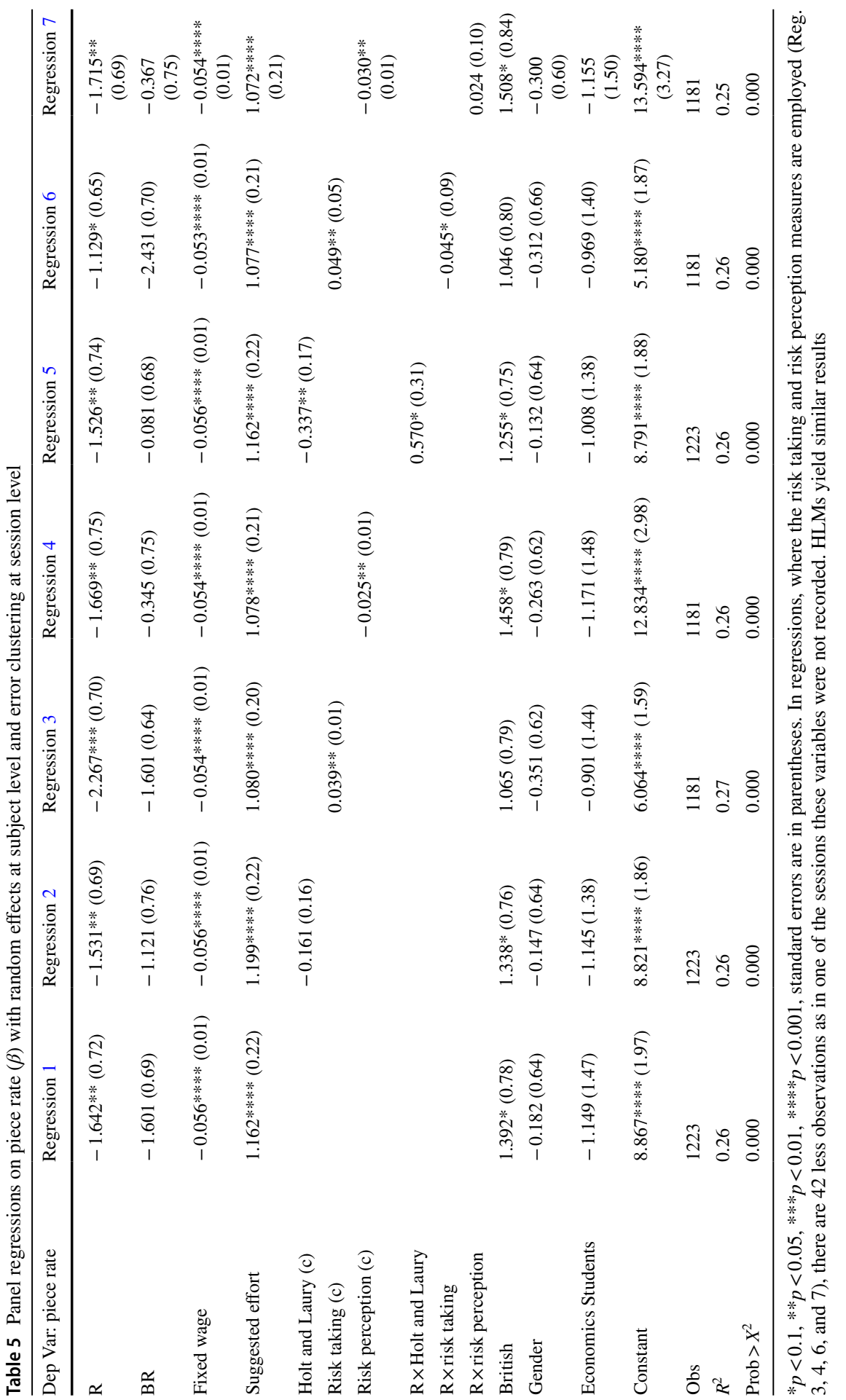




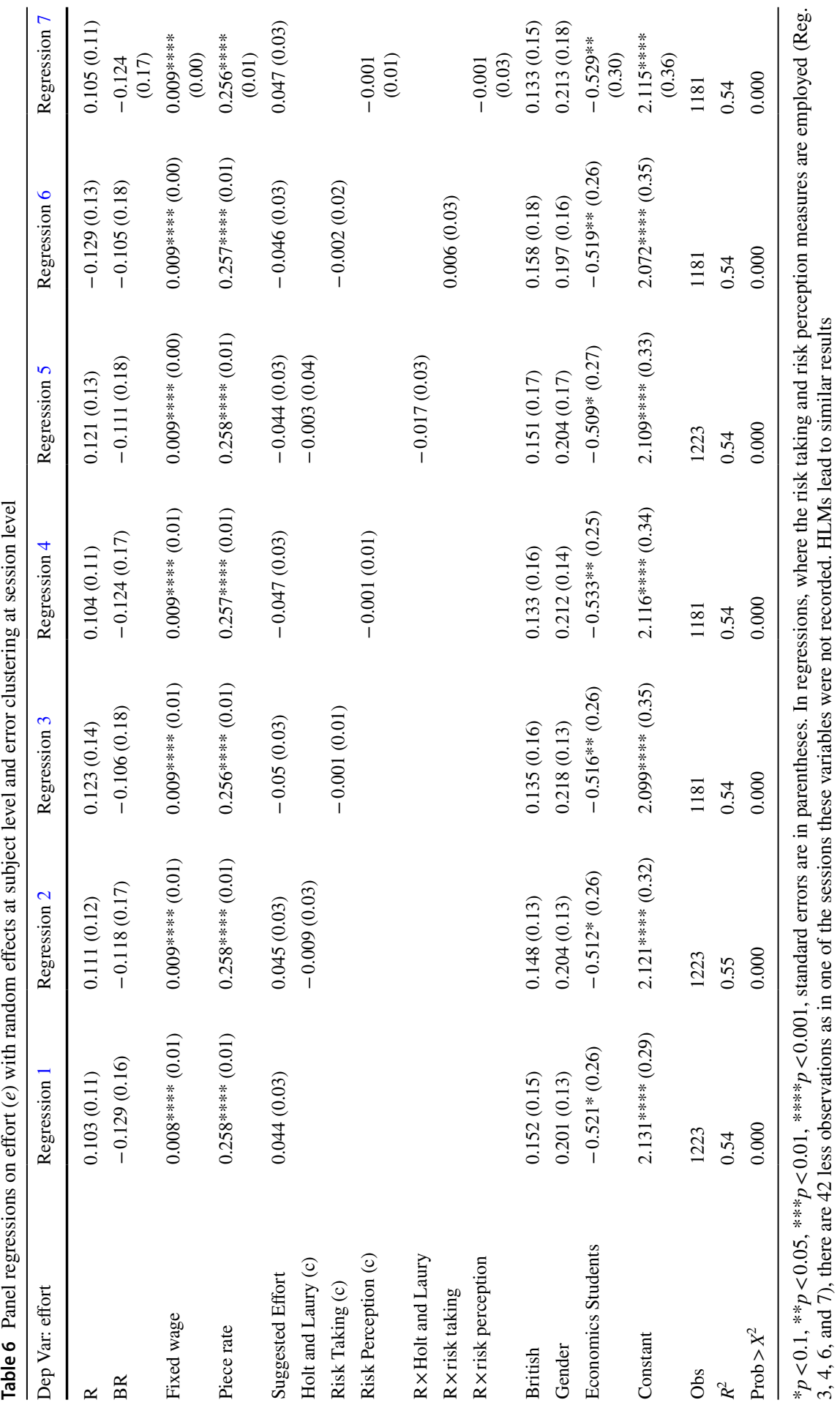


used dummy variables for nationality, gender, and economics students. We retained one observation per round for each subject, i.e., a total of 1223 observations. ${ }^{10}$

The results from the regressions on piece rate in Table 5 are in parallel with the findings of the non-parametric tests. In particular, in all the regressions that are presented in Table 5, the coefficient for the R treatment dummy is negative and statistically significant at the 5\% level: reinstating Result 1 that the higher the noise in the environment the smaller the piece rate offered by the employers.

The coefficient for the control treatment (BR) dummy is not statistically significant: as found in the non-parametric tests. Moreover, post-regression tests suggest no statistically significant difference between the BR and R treatments: suggesting that our implementation of Principal's risk neutrality worked as we hypothesized, and the result is robust.

Result 3 There is no statistically significant difference between the average piece rate offered in the $\mathrm{R}$ treatment and the BR treatment.

In regressions 2-4 in Table 5, we find that risk aversion has no impact on the size of the piece rate. However, after we introduced interaction variables between the risk treatment and each of the risk elicitation measures, we observe a statistically significant impact of the risk aversion coefficients both for the Holt and Laury (2002) task and the risk taking questionnaires. This provides our next result.

Result 4 In line with Hypothesis 3, assuming social projection, the more risk averse the principal believes the agent is, the smaller the piece rate s/he offers.

In addition, we find, as observed in Table 5, that the principals' view fixed wage and piece rate as substitutes. As a result, the coefficient for fixed wage is negative and statistically significant. The suggested effort is strongly correlated with the piece rate-indicating both an expectation of the principal and possibly his/her understanding of the convex cost function of the agents. The coefficients for the demographic controls are not significant except the British dummy, which is positive and weakly significant. This may possibly reflect the cultural/social differences (relatively costly labor, minimum wage restrictions, etc.) of the British students relative to the international students.

Turning our attention to the regressions on the effort levels in Table 6, we observe that none of the treatment dummies have significant effect in the effort levels. This is in line both with the theory and the findings of C-HG and Sloof and van Praag (2008).

Result 5 In line with Hypothesis 2, the effort choices of the agents are not affected by the introduction of variance in the performance measure.

We also find statistically significant positive coefficients for both the piece rate and the fixed wage. The first finding is in line with the model's prediction and payoff maximizing behavior. However, significant positive coefficients for fixed wage contradict with the standard theory, as well as the findings of C-HG and Sloof and van Praag (2008). Given that we have implemented a stated effort, this result could be

\footnotetext{
${ }^{10}$ In one of the sessions due to a technical problem the choices of the subjects on the psychology questionnaires were not recorded, as a consequence in the regressions which employ the psychology questionnaires as a dependant variable there are 1218 observations as that session is omitted.
} 
explained through social preferences and/or reciprocal behavior [see, for, e.g., Fehr et al. (1998)] of the agents. These are summarized formally in the following results.

Result 6 In line with Hypothesis 2, the agents responded with higher effort, and the higher the piece rate offered by the principals.

Result 7 In contrast to Hypothesis 2, the agents responded with higher effort the higher the fixed wage offered by the principals.

None of the other explanatory variables and controls are significant. Implying that a suggested effort (given fixed wage and piece rate) does not affect the effort choice. Furthermore, demographic factors, e.g., nationality, gender do not affect the effort choice.

\section{Discussion}

An important theory in personnel economics, the Incentive Intensity Principle, states that as volatility in performance increases, performance driven contracts should be employed less. Empirical evaluation of this theory until date has provided mixed results. However, since field data may include confounding factors and lack controls, the results might not be free from noise. Laboratory experiments can eliminate such issues. In this study, we investigate the relationship between risk and incentives through a principal-agent experiment.

This is only the second experimental study in this area after C-HG, who implement a real-effort task and find broad support for the theory. They explain some deviations in their findings with the canonical model with loss aversion. Our findings with respect to the relationship between risk and incentive intensity are in line with C-HG and provide further support for the predictions of the IIP. This also confirms the argument that the empirical studies, which found a positive or no relationship, may have been due to the variety of other confounding factors. Consequently, our findings provide support to theorists who introduced alternative dimensions or additional variables to explain the observed positive relationship in the previous studies (e.g., Prendergast 2002; Wright 2004; Budde and Kräkel 2011).

Supporting the model's prediction, we find no relationship between the variance in the performance and the effort choice of the agent. Furthermore, we find a positive relationship between effort and the size of the piece rate offered (ceteris paribus), which is in line with the predictions of the model, and more generally with the assumption of payoff maximizing behavior found in the literature on incentive contracts (Anderhub et al. 2002; Corgnet and Hernán-González 2018; Karakostas et al. 2017; Sloof and van Praag 2010).

In addition, we observe that whereas the level of effort in NR is significantly lower than the value predicted by the theory, it is still higher than in treatment $\mathrm{R}$. This result differs from Sloof and van Praag (2010) and C-HG who employ real-effort tasks, suggesting that a higher level of effort in a risky environment can be explained if agents are loss averse. Agents may exert a higher effort to increase the probability of being above their reference earnings level. However, this may not be possible when the (stated) 
effort, as in our setting, has a monetary cost. In this case, increasing the level of effort may not help to obtain higher earnings. Hence, our result can shed light on how different tasks provide diverse results through different mechanisms. As this suggests that using stated rather than real effort may lead to deviations in effort choices, the impact of the two methods in behavior is worthy of further scrutiny.

Moreover, the agents respond positively to higher fixed wages by exerting more effort-contradicting both the standard theory, and the experimental findings. This result, however, is consistent with the previous studies on labor contracts in which agents hold social and reciprocal preferences. Indeed, such a positive relationship between the fixed wage and effort is observed in the existing experimental studies on gift exchange (Fehr et al., 1998; Fehr and Schmidt 1999; Fehr and Gächter 2002; Fehr and Schmidt, 2004, 2007).

Hence, our experiment supports the comparative statics but not the point estimates predicted by the theory. However, this is not uncommon in 'theory-testing' experiments, where the micro-foundation of behavior is reflected through treatment effects, but possible noises (e.g., mistakes, preferences) distributed symmetrically across treatments make deviations from the point estimates (Anderhub et al. 2002; Fehr and Schmidt 2004; Hoppe and Schmitz 2015).

Adding to the (thin) existing literature, we introduced a treatment in which both the principal and the agent faced risk. We find that the results from this treatment are not different from the treatment in which only the agent faces risk, and the principal is insured. This result will allow future studies to abstract away from the issues relating to the principal being risk averse and to use simplified design while focusing on their specific research questions.

However, we also observe that the majority of the offers in the no risk treatment were with a suboptimal piece rate, which is in stark difference with the existing studies. A potential explanation for such lower offers may be due to our implementation of a minimum wage, which may have acted as a reference point for the employers driving downwards the offers of the principals. However, since minimum wage is a real-life phenomenon, this is an important observation as well as an interesting avenue for future research.

In conclusion, we test the predictions of the IIP in a laboratory setting in which we employ a stated-effort task, check the robustness of insuring the principal or not, and introduce the concept of social projection. We find support for the negative relationship between risk and incentives and our results are broadly in line with the existing experimental literature. However, we also find some significant and interesting differences with the existing studies that reiterate the importance of laboratory experiments in testing and extending theory. Our study can be extended in various ways. An interesting extension, for example, would be to allow the subjects to form reputation in a repeated setting, therefore, more accurately reflecting the real world. 
Open Access This article is distributed under the terms of the Creative Commons Attribution 4.0 International License (http://creativecommons.org/licenses/by/4.0/), which permits unrestricted use, distribution, and reproduction in any medium, provided you give appropriate credit to the original author(s) and the source, provide a link to the Creative Commons license, and indicate if changes were made.

\section{Appendix A: the P-A and theoretical predictions}

\section{The parameters of experimental implementation}

There are two individuals: a principal $\mathrm{P}$ and an agent $\mathrm{A}$. The principal wants to hire the Agent to exert effort $e$. For every unit of effort exerted by the agent the principal earns 50 ECU. However, effort is costly for the agent and the cost function is given by $C(e)$. The principal uses a linear incentive scheme to hire the agent.

\section{Case with no risk}

When there is no risk, and effort is observable, then the principal's profit function is defined as

$$
P^{\mathrm{P}}=R(e)-[F+\beta e] .
$$

The agent's payoff when there is no risk is defined as

$$
P^{\mathrm{A}}=F+\beta e-C(e) .
$$

The total revenue is given by

$$
R(e)=50 e \text {. }
$$

The cost of effort is a strictly increasing and convex function in effort:

$$
C(e)=e^{2} \text {. }
$$

With:

$F \quad$ Unconditional fixed wage, where $F \in\{50,51, \ldots, 199,200\}$

$\beta$ The piece rate paid to the agent for each unit of effort, where $\beta \in\{5,6, \ldots, 39,40\}$

$e \quad$ Effort level revealed by the agent, where $e \in\{5,6, \ldots, 9,10\}$

Given the above parameters the participation constraint, i.e., the constraint that has to be met to make any contract offer monetarily beneficial for the agent is

$$
F+\beta e \geq C(e) .
$$

Any offer that does not satisfy (5) if accepted would imply the agent would make losses.

The principal offers a tuple $\{F, \beta\}$ and wants to

$$
\max (R(e)-F-\beta e) .
$$


Given that the agent would accept any contract that satisfies (5), the minimum amount that has to be transferred to the agent has to be equal to $C(e)$. Hence

$$
F+\beta e=C(e) .
$$

The principal's maximization problem becomes

$$
\max (R(e)-C(e)) \text {. }
$$

Inserting the actual parameters and functional forms used in the experiment, this results in

$$
\max \left(50 e-e^{2}\right) .
$$

Maximizing by $e$ results in: $e=25$

Thus, the optimal effort level for the principal would be 25 . As the experimental parameters only allow $e \in\{5,6, \ldots, 9,10\}$, the problem in (6) has a corner solution $^{11}$ of $e^{*}=10$.

Maximizing the agent's payoff in (2) with respect to $e^{*}$ leads to

$$
\beta-2 e^{*}=0 \Rightarrow \beta=2 e^{*} .
$$

Inserting the above calculated effort level $e^{*}=10$ and solving for $\beta$, finally provides the minimum piece rate $\beta^{*}$. Thus

$$
\beta^{*}=20
$$

Thus, the incentive contract is incentive compatible for any value of $\beta \geq 20$.

With $\beta=\beta^{*}$, the consequent profits (after taking into account their endowments) for the principal $P^{\mathrm{P}}=450$ and $P^{\mathrm{A}}=350$ for the agent.

\section{Case with risk}

When there is risk in the environment the principal is assumed to be able to observe the final output (i.e., total revenue), but s/he is unable to observe what part of this output is due to the agent's effort and what is due to randomness. In this case, the total revenue function can be expressed the following way:

$$
R(e)=50(e+x) .
$$

With:

$x \quad$ Stochastic random factor, where $x \sim N(0,2.5)$

Assuming the principal to be risk neutral s/he will maximize the expected payoff:

$$
E\left(P^{\mathrm{P}}\right)=R(e)-(F+\beta(e+x)) .
$$

\footnotetext{
11 The choice for a corner solution was made to reduce complexity to an already highly complex design from the perspective of the principal. This choice though bears the cost that will be harder to test if the principals had correctly identified that $e^{*}$ is the optimum effort level or if they chose it ad hoc simply following a rule of thumb such as the more the better. Nevertheless, the use of corner solutions has often been a common approach to experiments which investigated contract design and social preferences.
} 
Given the principal is risk neutral and $x \sim N(0,2.5)$, the payoff function of the principal can be re-written as

$$
E\left(P^{\mathrm{P}}\right)=50 e-(F+\beta e) .
$$

However, given that the agent is risk averse, his or her expected payoff is given by

$$
E\left(P^{\mathrm{A}}\right)=F+\beta e-C(e)-\frac{1}{2} r \beta^{2} \operatorname{var}(x),
$$

where $r$ is the coefficient of absolute risk aversion of the agent.

Given the payoff functions (10) and (11), Holmstrom and Milgrom (1987), have shown that the optimal incentive intensity $\beta$ is given by: $\beta=\frac{R^{\prime}(e)}{1+r V C^{\prime \prime}(e)}$, where $V=\operatorname{var}(x)$.

Proof The agent will choose $e$ to maximize his/her expected profit $E\left(P^{\mathrm{A}}\right)$.

F.O.C.

$$
\beta=C^{\prime}(e) \text { (Incentive Compatibility Constraint). }
$$

Given that the agent's reservation utility is assumed to be $200 \mathrm{ECU}$, the principal needs to satisfy the following participation constraint:

$$
F+\beta e \geq C(e)+\frac{1}{2} r \beta V+200 .
$$

In equilibrium, this will be strict equality. Principal's net profit is given by $P^{\mathrm{P}}=R(e)-(F+\beta e)$, substituting Eq. (13) leads to $P^{\mathrm{P}}=R(e)-C(e)-\frac{1}{2} r \beta V$, substituting Eq. (12) for $\beta$

$$
P^{\mathrm{P}}=R(e)-C(e)-\frac{1}{2} r C^{\prime}(e)^{2} V .
$$

F.O.C.

$$
\begin{gathered}
\frac{\partial P^{\mathrm{P}}}{\partial e}=R^{\prime}(e)-C^{\prime}(e)-r V C^{\prime}(e) C^{\prime \prime}(e)=0 \Rightarrow \\
R^{\prime}(e)=C^{\prime}(e)+r V C^{\prime}(e) C^{\prime \prime}(e) \Rightarrow
\end{gathered}
$$

$R^{\prime}(e)=C^{\prime}(e)\left[1+r V C^{\prime}(e)\right]$, substituting $\beta$ for $C^{\prime}(e)$

$R^{\prime}(e)=\beta\left[1+r V C^{\prime}(e)\right]$ and solving for $\beta$

$$
\beta=\frac{R^{\prime}(e)}{1+r V C^{\prime \prime}(e)} .
$$

Given that $V$ in our experiment was set at 2.5 and the rest of the factors remained unchanged the optimal $\beta^{*}$ is given by

$$
\beta^{*}=\frac{50}{1+5 r} \text {. }
$$


We elicited the coefficient of constant absolute risk aversion for all subjects using the Holt and Laury (2002) questionnaire. To generate a benchmark for our analysis, we calculated an average $\bar{r}$ from all subjects in our experiment. The average coefficient of absolute risk aversion from all subjects who participated in our experiment was $\bar{r}=0.549$. After inserting $\bar{r} \bar{r}$ in Eq. (1), it yields the optimal $\beta^{*}=13.35$. Given $\beta^{*}$, the optimal effort level $e$ for the employee is 7. However, as the participants in our subject pool could select only one decimal, the second best choice of $\beta^{*}$ is 13.4. Consequently, the expected profits (including endowments) for the principal and the agent, respectively, are: $P^{\mathrm{P}}=516$ and $P^{\mathrm{A}}=384$.

\section{Appendix B: instructions}

Welcome to our experiment! You are participating in an experiment on decision making. The experiment is expected to last no more than $1 \mathrm{~h}$ and $15 \mathrm{~min}$. Please read the following instructions carefully. During the experiment, you are not allowed to communicate with other participants. If you face any questions at any moment, please raise your hand and the experimenter will come to your desk.

In the experiment, you will be using an experimental currency called ECU. In the end of the experiment, the ECU you have earned during the experiment will be converted at the exchange rate of: $1 \mathrm{ECU}=£ 0.02$.

For example, $10 \mathrm{ECU}=£ 0.20,100 \mathrm{ECU}=£ 2,50 \mathrm{ECU}=£ 1,200 \mathrm{ECU}=£ 4$.

\section{Experiment overview}

The experiment consists of two parts. The first part is explained in detail bellow the second consists of two questionnaires and will be explained at the end of the first part.

The first part of the experiment consists of ten rounds. The first three rounds are practice rounds, and this means that your choices will not affect your earnings. Their role is to help you understand and familiarise with the tasks involved. One from the following seven rounds will be chosen randomly by the computer and paid to you in cash at the end of the experiment.

Each participant is assigned randomly the role of either the employer or the employee. You hold this role throughout the experiment. If you are an employer, the computer will randomly match you with an employee at the start of every round and if you are an employee with an employer. The experiment is anonymous; this means that you will not know with whom of the other participants you are interacting. 
Table 7 Effort levels, cost of effort, and employer revenue

\begin{tabular}{lll}
\hline Effort & Cost of effort & $\begin{array}{l}\text { Employer } \\
\text { revenue }\end{array}$ \\
\hline 5 & 25 & 250 \\
6 & 36 & 300 \\
7 & 49 & 350 \\
8 & 64 & 400 \\
9 & 81 & 450 \\
10 & 100 & 500 \\
\hline
\end{tabular}

\section{The structure of a round}

1. The employer has to offer an employment contract to the employee requesting $\mathrm{him} /$ her to exert a level of effort.

2. The employee decides to accept or reject the contract:

a. If he/she rejects the contract the round finishes and both earn 200 ECU.

b. If the employee accepts the contract both receive the $200 \mathrm{ECU}$ and he/she decides what effort level he/she wants to exert.

3. After the employee has chosen an effort level, the computer calculates the profits of both and the round finishes.

\section{The contract}

If you are an employer, you need to decide what effort level you want the employee to exert. After you decide the effort, you would want the employee to exert you need to think what contract to offer to the employee given the implications that this has in earnings. If you are the employee, what you need to think is what effort you would want to exert for the given contract taking into account the effect this has on earnings.

At the start of every round, both employer and employee receive 200 ECU. This money is for you to use within the experiment and is added to your profits for the round.

Effort in this experiment is represented by a number the employee chooses which ranges from 5 to 10 . Every unit of effort costs ECU to the employee. Table 7 shows the corresponding employer revenue and cost of effort for each unit of effort.

The revenue of the employer is determined by the following:

Revenue of the employer: $50 \times$ effort.

That means that for every unit of effort, the employee exerts the employer earns 50 ECU. For example, if the employee exerts an effort of 3, the employer earns 150 ECU.

Employers can choose to pay the employee with a fixed wage and/or with a piece rate. 
A fixed wage is a transfer of money from the employer to the employee which is independent of how much effort he/she exerts (for example, a salary). The fixed wage can range from 50 to 200 ECU.

A piece rate is a payment for every unit of effort. An example of that could be an apple picker. If the employee was an apple picker, a piece rate would mean a specific amount of money (ECU) for every basket of apples (effort) that he brings to the employer. For example, for a piece rate of 20 and an effort level of 5, the employee will be paid $20 \times 5=100$ ECU, i.e., the employee earns $100 \mathrm{ECU}$ (the piece rate can range from 5 to 40 including one decimal (i.e., 10.1, 23.4, 30.5, etc.).

\section{Suggested effort}

In his/her contract offer, the employer has to suggest an effort level to the employee. Note, however, that the suggested effort of the employer is only a suggestion. The employee is not bound to that suggestion, but he/she is free to choose any effort level within the given range of 5-10.

\section{The minimum contract}

The minimum effort of the employee is 5. To ensure that the employee is at least compensated for his/her minimum effort the contract offered by the employer must have a minimum fixed wage of $50 \mathrm{ECU}$ and a piece rate of 5 .

\section{How earnings from a round are calculated}

For the employer his/her earnings are the 200 ECU, he received at the start of the round, plus the revenue generated by the employee's effort, minus the fixed wage he/ she paid, and minus the piece rate he/she paid. In other words:

Employer's Earnings $=200$ ECU + Revenue - Fixed Wage - Piece Rate $\mathbf{x}$ Effort

In the case of the employee, his/her earnings are his/her $200 \mathrm{ECU}$ plus the fixed wage plus the piece rate times the effort, minus the cost of effort. In other words:

Employee's Earnings $=200$ ECU + Fixed Wage + Piece Rate $\mathbf{x}$ Effort - Cost of Effort 


\section{Overview}

0. The employer chooses the fixed wage (from 50 to 200 ), the piece rate (5-40), and suggests an effort level (from 5 to 10) to the employee.

1. Afterwards, the employee has been informed of the offered contract, and he/she has to decide either to accept or reject the contract. If the employee rejects the contract, the stage finishes. If he accepts the contract, he receives the offered fixed wage and decides an effort level (from 5 to 10).

2. Once the employee has decided an effort level, the computer calculates the earnings of the employer and the employee and informs both participants.

3. This procedure is repeated until we reach round 10 .

\section{Some examples}

Think the following examples carefully and try to see if the earnings have been calculated correctly. The numbers chosen are purely illustrative.

\section{Example 1:}

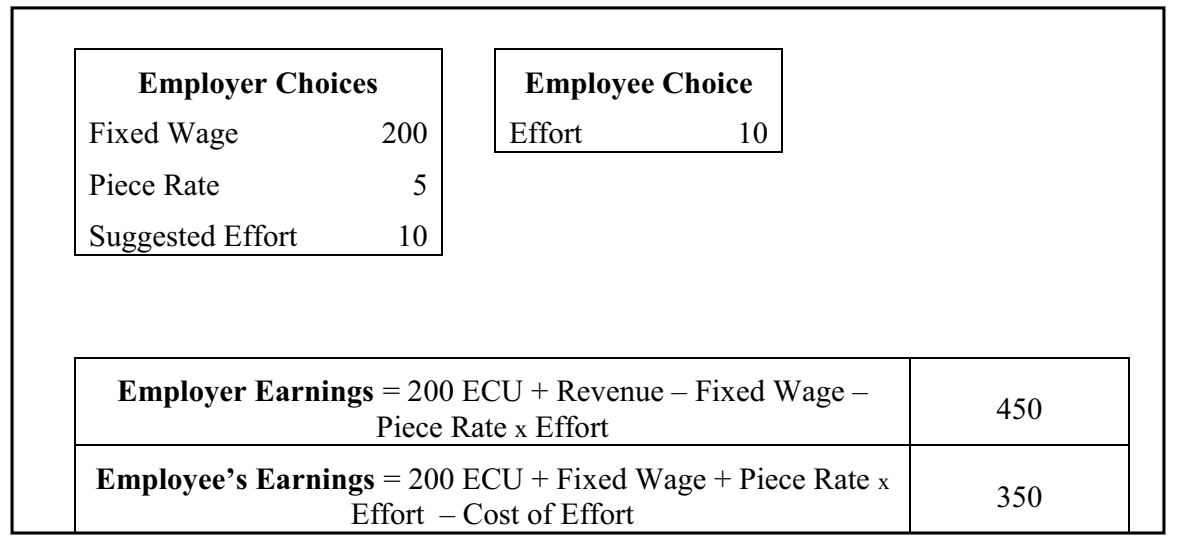

\section{Example 2:}




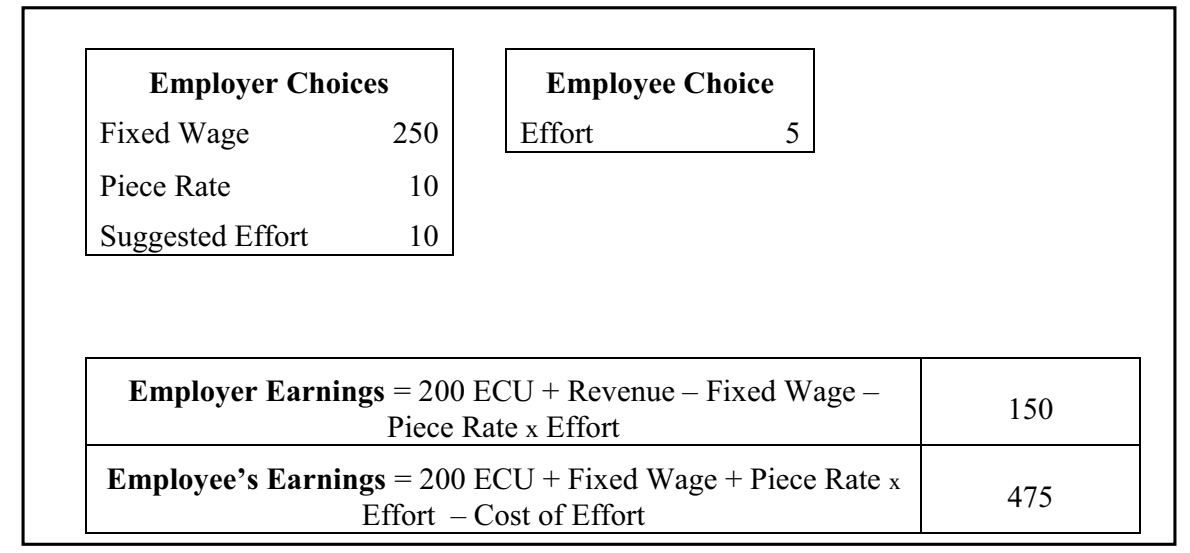

\section{Example 3:}

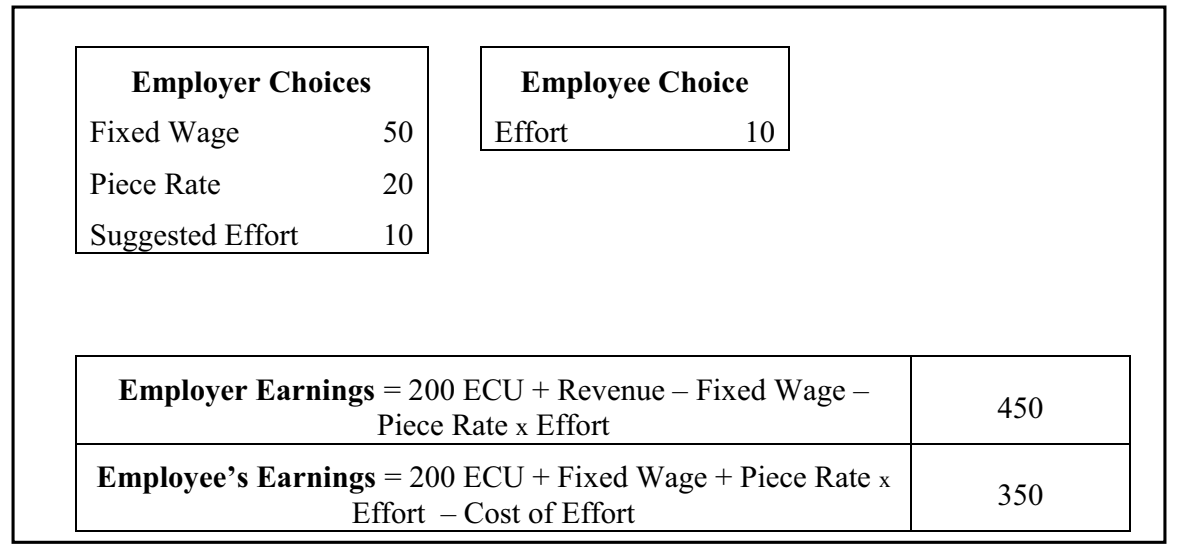

\section{Example 4:}




\begin{tabular}{|lr|}
\hline \multicolumn{2}{|c|}{ Employer Choices } \\
Fixed Wage & 50 \\
Piece Rate & 30 \\
Suggested Effort & 8 \\
\hline
\end{tabular}

\begin{tabular}{|l|}
\hline \multicolumn{2}{|c|}{ Employee Choice } \\
Effort $\quad 10$ \\
\hline
\end{tabular}

\begin{tabular}{|c|c|}
\hline Employer Earnings $=200$ ECU + Revenue - Fixed Wage - & 350 \\
Piece Rate x Effort & 450 \\
\hline $\begin{array}{c}\text { Employee's Earnings }=200 \text { ECU + Fixed Wage + Piece Rate } x \\
\text { Effort }- \text { Cost of Effort }\end{array}$ & 450 \\
\hline
\end{tabular}

\section{Example 5:}

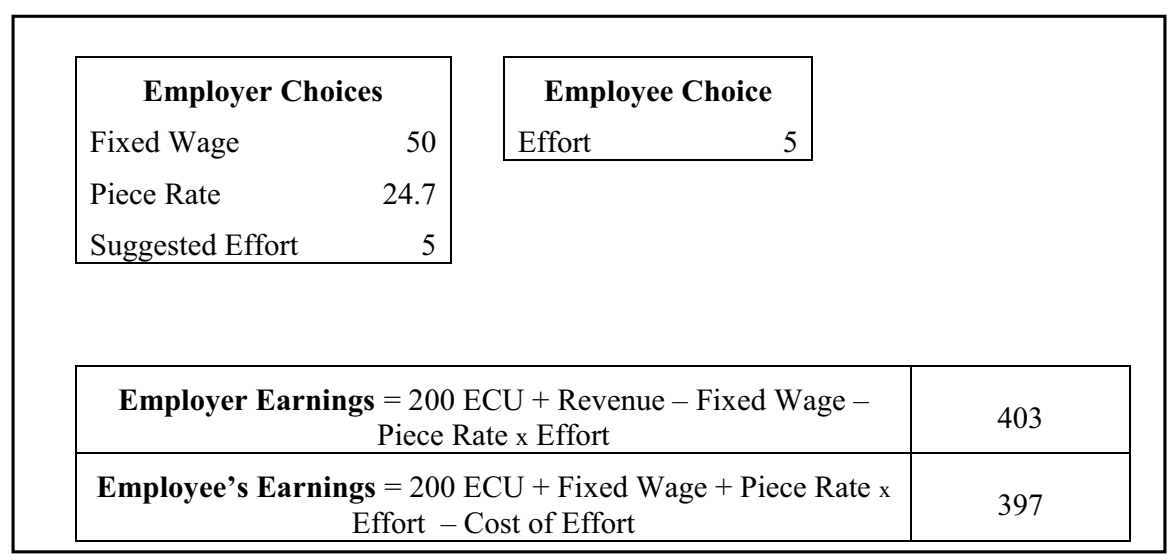

\section{Instructions (R treatment)}

Welcome to our experiment! You are participating in an experiment on decision making. The experiment is expected to last no more than $1 \mathrm{~h}$ and $15 \mathrm{~min}$. Please read the following instructions carefully. During the experiment, you are not allowed to communicate with other participants. If you face any questions at any moment, please raise your hand and the experimenter will come to your desk. 
In the experiment, you will be using an experimental currency called ECU. In the end of the experiment, the ECU you have earned during the experiment will be converted at the exchange rate of: $1 \mathrm{ECU}=£ 0.02$.

For example, $10 \mathrm{ECU}=£ 0.20,100 \mathrm{ECU}=£ 2,50 \mathrm{ECU}=£ 1,200 \mathrm{ECU}=£ 4$.

\section{Experiment overview}

The experiment consists of two parts. The first part is explained in detail bellow the second consists of two questionnaires and will be explained at the end of the first part.

The first part of the experiment consists of ten rounds. The first three rounds are practice rounds, and this means that your choices will not affect your earnings. Their role is to help you understand and familiarise with the tasks involved. One from the following seven rounds will be chosen randomly by the computer and paid to you in cash at the end of the experiment.

Each participant is assigned randomly the role of either the employer or the employee. You hold this role throughout the experiment. If you are an employer, the computer will randomly match you with an employee at the start of every round and if you are an employee with an employer. The experiment is anonymous; this means that you will not know with whom of the other participants you are interacting.

\section{The structure of a round}

1. The employer has to offer an employment contract to the employee requesting him/her to exert a level of effort.

2. The employee decides to accept or reject the contract:

a. If he/she rejects the contract, the round finishes and both earn $200 \mathrm{ECU}$.

b. If the employee accepts the contract, both receive the $200 \mathrm{ECU}$ and he/she decides what effort level he/she wants to exert.

3. After the employee has chosen an effort level, the computer calculates the profits of both and the round finishes.

\section{The contract}

If you are an employer, you need to decide what effort level you want the employee to exert. After you decide, the effort you would want the employee to exert you need to think what contract to offer to the employee given the implications that this has in earnings. If you are the employee, what you need to think is what effort you would want to exert for the given contract taking into account the effect this has on earnings.

At the start of every round, both employer and employee receive 200 ECU. This money is for you to use within the experiment and is added to your profits for the round. 
Table 8 Chance of each luck factor to happen

\begin{tabular}{ll}
\hline Luck & Chance (\%) \\
\hline-5 & 1 \\
-4 & 4 \\
-3 & 7 \\
-2 & 12 \\
-1 & 16 \\
0 & 20 \\
1 & 16 \\
2 & 12 \\
3 & 7 \\
4 & 4 \\
5 & 1 \\
\hline
\end{tabular}

Effort in this experiment is represented by a number the employee chooses, which ranges from 5 to 10. Every unit of effort costs ECU to the employee. Table 7 shows the corresponding employer revenue and cost of effort for each unit of effort.

The revenue of the employer is determined by the following:

Revenue of the employer: $50 \times$ effort.

That means that for every unit of effort the employee exerts, the employer earns 50 ECU. For example, if the employee exerts an effort of 3, the employer earns 150 ECU.

Employers can choose to pay the employee with a fixed wage and/or with a piece rate.

A fixed wage is a transfer of money from the employer to the employee, which is independent of how much effort he/she exerts (for example, a salary). The fixed wage can range from 0 to 200 ECU.

A piece rate is a payment for every unit of output. Output is the sum of effort + a luck value. An example of that could be an apple picker. If the employee was an apple picker a piece rate would mean a specific amount of money (ECU) for every basket of apples (output) s/he brings to the employer. In addition, the luck factor could be how favourable or unfavourable the weather conditions has been. The piece rate can range from 5 to 40. For example, for a piece rate of 10 , an effort level of 3 , and a luck value of 2 , it means that the employee will be paid $10 \times(3+2)=50$, i.e., the employee earns 50 ECU.

Table 8 shows the values luck may take (that is from -5 to 5 ) and what is the chance for each of these values to be selected by the computer. For example, the chance the luck value to turn out to be -5 is one out of a hundred, for -1 is 16 out of a hundred, for 2 is 12 out of a hundred, etc.

The earnings for the employee from the piece rate are calculated by the ECU value chosen from the employer (from 5 to 40) multiplied by the output, which is the sum of the effort and luck [i.e., piece rate $\times($ effort + luck $)$ ]. Note that luck only affects the earnings of the employee. 
An example (numbers are purely illustrative)

Assume: (a) the employer chooses to set the piece rate at the value of 5 and (b) the employee chooses an effort of 5 and the luck value turns out to be -2 .

The employees from the piece rate are the piece rate times the sum of effort and luck [i.e., $5 \times(5+(-2))=5 \times 3=15$ ], which is $15 \mathrm{ECU}$ plus the $100 \mathrm{ECU}$ minus the cost of effort for 5 units of effort, which is 28 . Therefore, the employee will earn $115-28$, which is 87 ECU.

For the employer, however, the earnings are calculated without considering the luck value. Therefore, the employer will receive $25 \times 5$ (the revenue from 5 units of effort) minus the piece rate, which will be 5 (the piece rate) times the effort of the employee, which was 5 plus the $100 \mathrm{ECU}$ that is given to him at the start of the round. Hence, $125-25+100$ leads to earnings of 100 ECU.

\section{Suggested effort}

In his/her contract offer, the employer has to suggest an effort level to the employee. Note, however, that the suggested effort of the employer is only a suggestion. The employee is not bound to that suggestion but he/she is free to choose any effort level within the given range of $0-5$.

\section{The minimum contract}

The minimum effort of the employee is 5. To ensure that the employee is at least compensated for his/her minimum effort the contract offered by the employer must have a minimum fixed wage of $50 \mathrm{ECU}$ and a piece rate of 5.

\section{How earnings from a round are calculated}

For the employer, his/her earnings are the $200 \mathrm{ECU}$ s/he received at the start of the round, plus the revenue generated by the employee's effort, minus the fixed wage he/ she paid, and minus the piece rate he/she paid. In other words:

Employer's Earnings $=200$ ECU + Revenue - Fixed Wage - Piece Rate $\mathbf{x}$ Effort

In the case of the employee, his/her earnings are his/her $100 \mathrm{ECU}$ plus the fixed wage plus the piece rate times the sum of effort and the luck factor, minus the cost of effort. In other words: 
Employee's Earnings $=200$ ECU + Fixed Wage + Piece Rate $\mathbf{x}($ Effort + luck $)-$ Cost of Effort

Note that the luck factor affects only the employee!

\section{Overview}

1. The employer chooses the fixed wage (from 50 to 200 ), the piece rate (5-40), and suggests an effort level (from 5 to 10) to the employee.

2. Afterwards, the employee has been informed of the offered contract, and he/she has to decide either to accept or reject the contract. If the employee rejects the contract, the stage finishes. If s/he accepts the contract, s/he receives the offered fixed wage and decides an effort level (from 5 to 10).

3. Once the employee has decided an effort level, the computer calculates the earnings of the employer and the employee and informs both participants.

4. This procedure is repeated until we reach round 10 .

\section{Some examples}

Think of the following examples carefully and try to see if the earnings have been calculated correctly. The numbers chosen are purely illustrative.

\section{Example 1:}




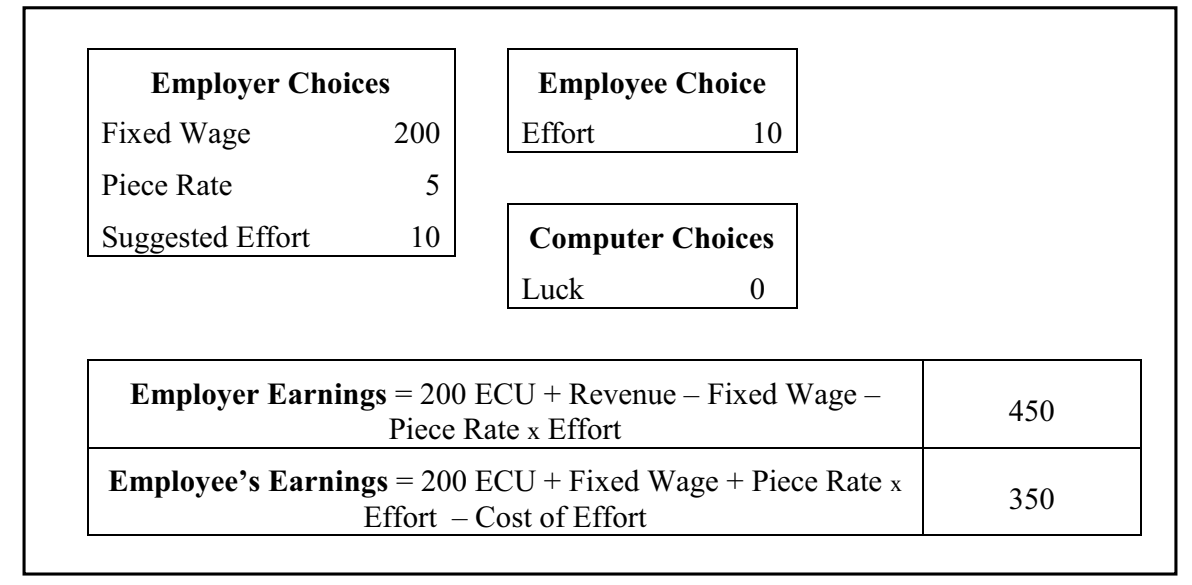

\section{Example 2:}

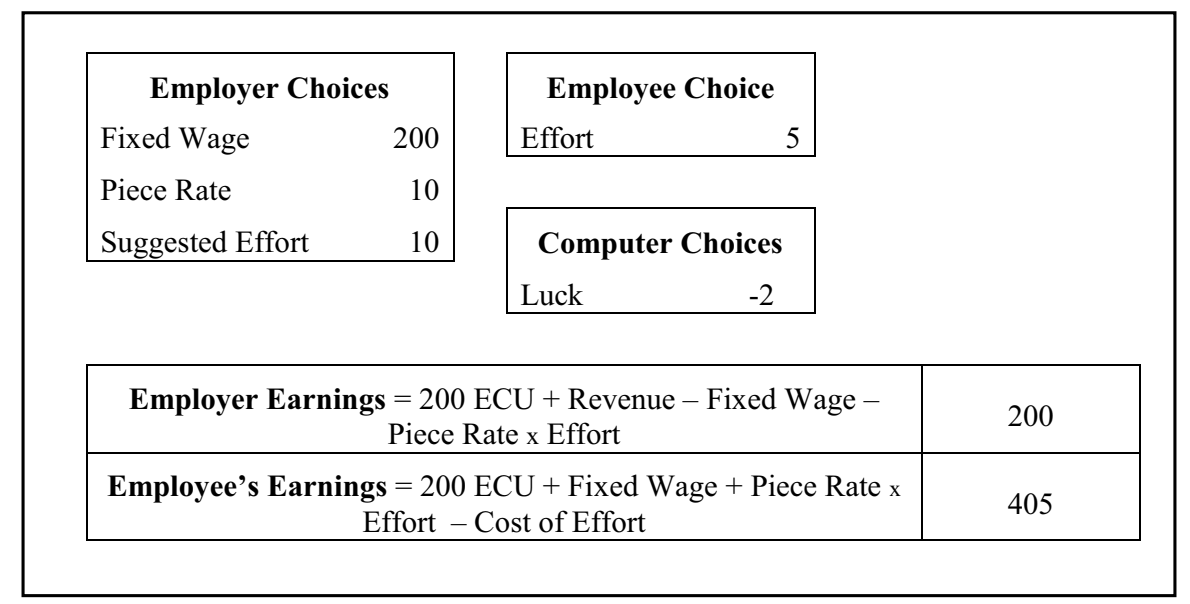




\section{Example 3:}

\begin{tabular}{|lr|}
\hline \multicolumn{2}{|c|}{ Employer Choices } \\
Fixed Wage & 50 \\
Piece Rate & 20 \\
Suggested Effort & 10 \\
\hline
\end{tabular}

\begin{tabular}{|lr|}
\hline \multicolumn{2}{|c|}{ Employee Choice } \\
Effort & 10 \\
\hline
\end{tabular}

\section{Computer Choices}

Luck

\begin{tabular}{|c|c|}
\hline Employer Earnings $=200$ ECU + Revenue - Fixed Wage - & 450 \\
Piece Rate x Effort & 390 \\
\hline $\begin{array}{c}\text { Employee's Earnings }=200 \text { ECU + Fixed Wage + Piece Rate x } \\
\text { Effort }- \text { Cost of Effort }\end{array}$ & 390 \\
\hline
\end{tabular}

\section{Example 4:}

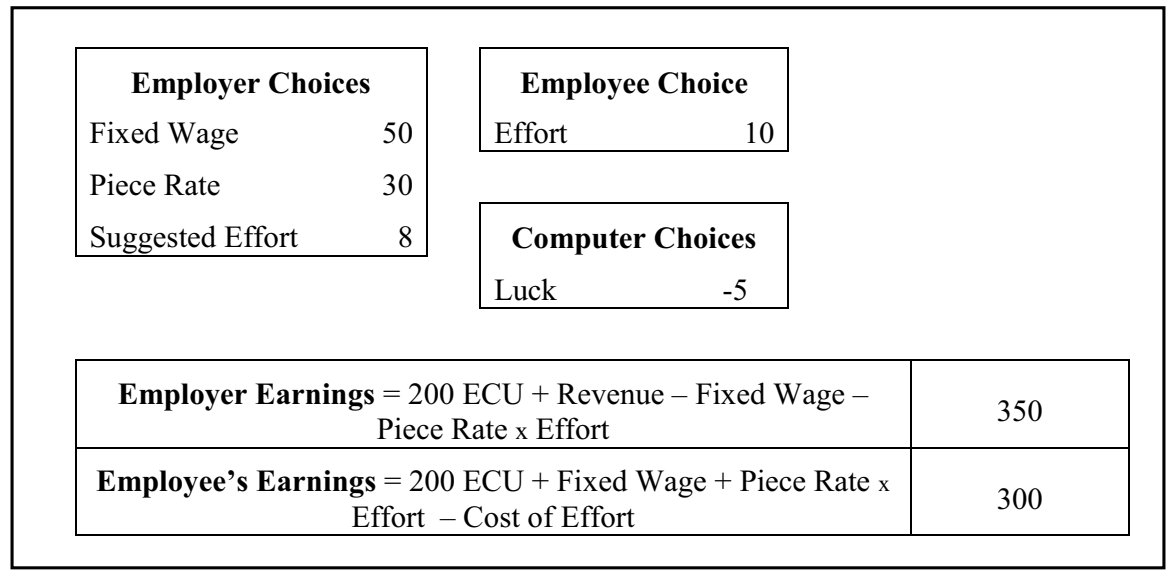

\section{Example 5:}




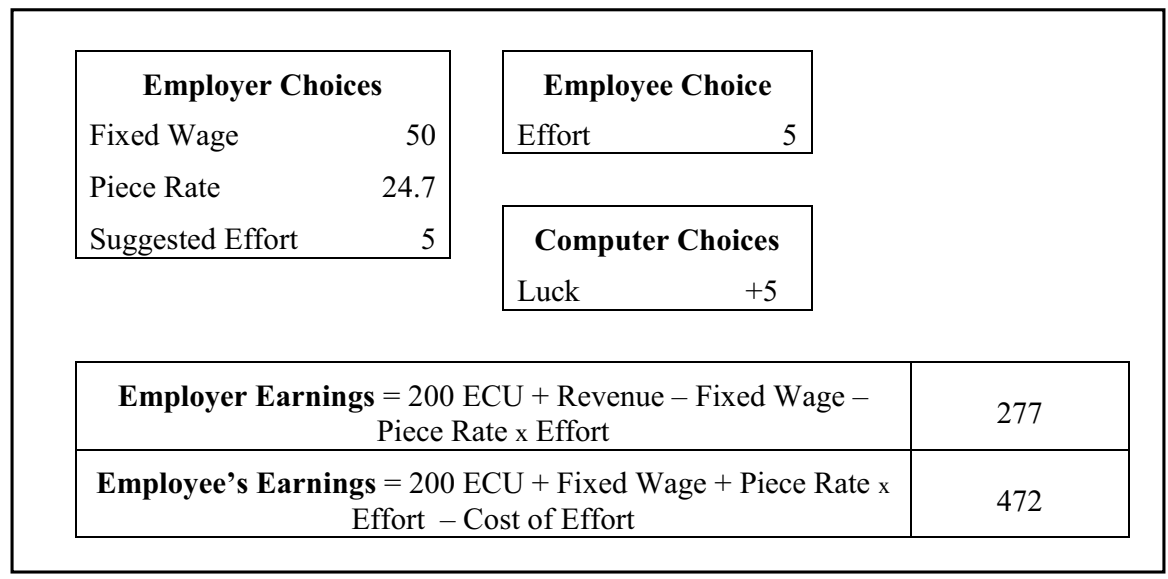

\section{Instructions (BR treatment)}

Welcome to our experiment! You are participating in an experiment on decision making. The experiment is expected to last no more than $1 \mathrm{~h}$ and $15 \mathrm{~min}$. Please read the following instructions carefully. During the experiment, you are not allowed to communicate with other participants. If you face any questions at any moment please raise your hand and the experimenter will come to your desk.

In the experiment, you will be using an experimental currency called ECU. In the end of the experiment, the ECU you have earned during the experiment will be converted at the exchange rate of: $1 \mathrm{ECU}=£ 0.02$.

For example, $10 \mathrm{ECU}=£ 0.20,100 \mathrm{ECU}=£ 2,50 \mathrm{ECU}=£ 1,200 \mathrm{ECU}=£ 4$.

\section{Experiment overview}

The experiment consists of two parts. The first part is explained in detail below the second consists of two questionnaires and will be explained at the end of the first part.

The first part of the experiment consists of ten rounds. The first three rounds are practice rounds, and this means that your choices will not affect your earnings. Their role is to help you understand and familiarise with the tasks involved. One from the following seven rounds will be chosen randomly by the computer and paid to you in cash at the end of the experiment.

Each participant is assigned randomly the role of either the employer or the employee. You hold this role throughout the experiment. If you are an employer the computer will randomly match you with an employee at the start of every round and if you are an employee with an employer. The experiment is anonymous; this means that you will not know with whom of the other participants you are interacting. 


\section{The structure of a round}

1. The employer has to offer an employment contract to the employee requesting $\mathrm{him} /$ her to exert a level of effort.

2. The employee decides to accept or reject the contract:

a. If he/she rejects the contract, the round finishes and both earn 200 ECU.

b. If the employee accepts the contract both receive the $200 \mathrm{ECU}$ and he/she decides what effort level he/she wants to exert.

3. After the employee has chosen an effort level that the computer calculates the profits of both and the round finishes.

\section{The contract}

If you are an employer, you need to decide what effort level you want the employee to exert. After you decide the effort, you would want the employee to exert you need to think what contract to offer to the employee given the implications that this has in earnings. If you are the employee, what you need to think is what effort you would want to exert for the given contract taking into account the effect this has on earnings.

At the start of every round, both employer and employee receive 200 ECU. This money is for you to use within the experiment and is added to your profits for the round.

Effort in this experiment is represented by a number the employee chooses, which ranges from 5 to 10. Every unit of effort costs ECU to the employee. Table 7 shows the corresponding employer revenue and cost of effort for each unit of effort.

The revenue of the employer is determined by the following:

Revenue of the employer: $50 \times($ effort + luck $)$.

Luck is a number that is randomly chosen by the computer and can range from -5 to 5 .

That means that for every unit of effort (assume luck is 0 ), the employee decides, and the employer earns 50 ECU. For example, if the employee decides an effort of 3. the employer earns 150 ECU.

Employers can choose to pay the employee with a fixed wage and/or with a piece rate.

A fixed wage is a transfer of money from the employer to the employee, which is independent of how much effort he/she exerts (for example, a salary). The fixed wage can range from 50 to $200 \mathrm{ECU}$.

A piece rate is a payment for every unit of output. Output is the sum of effort and the luck value. An example of that could be an apple picker. If the employee was an apple picker, a piece rate would mean a specific amount of money (ECU) for every basket of apples (output) that s/he brings to the employer. In addition, the luck factor could be how favourable or unfavourable the weather conditions have been. The piece rate can range from 5 to 40 . For example, for a piece rate of 10, an effort level 
of 5 , and a luck value of 2 , it means that the employee will be paid $10 \times(5+2)=70$, i.e., the employee earns 70 ECU.

Table 8 shows the values luck may take (that is from -5 to 5 ) and what is the chance for each of these values to be selected by the computer. For example, the chance the luck value to turn out to be -5 is one out of a hundred, for -1 is 16 out of a hundred, for 2 is 12 out of a hundred, etc.

The earnings for the employee from the piece rate are calculated by the ECU value chosen from the employer (from 5 to 40 ) multiplied by the output, which is the sum of the effort and luck [i.e., piece rate $\times($ effort + luck $)]$.

An example (numbers are purely illustrative)

Assume: (a) the employer chooses to set the piece rate at the value of 5 and (b) the employee chooses an effort of 5 and the luck value turns out to be -2 .

The employee's earnings from the piece rate are the piece rate times the sum of effort and luck [i.e., $5 \times(5+(-2))=5 \times 3=15$ ], which is $15 \mathrm{ECU}$ plus the $200 \mathrm{ECU}$ minus the cost of effort for 5 units of effort, which is 28 . Therefore, the employee will earn $215-28$, which is 187 ECU.

The employer will receive $50 \times(5-2)$, which equals to $150 \mathrm{ECU}$, minus the piece rate, which will be 15 plus the 200 ECU that is given to him at the start of the round. Hence, $150-15+200$ leading to earnings of 3250 ECU.

\section{Suggested effort}

In his/her contract offer, the employer has to suggest an effort level to the employee. Note, however, that the suggested effort of the employer is only a suggestion. The employee is not bound to that suggestion, but he/she is free to choose any effort level within the given range of 5-10.

\section{The minimum contract}

The minimum effort of the employee is 5. To ensure that the employee is compensated for his/her minimum effort, the contract offered by the employer must have a 
minimum fixed wage of $50 \mathrm{ECU}$ and a piece rate of 5. This way it is ensured that neither the employers nor the employees can make losses.

\section{How earnings from a round are calculated}

For the employer his/her earnings are the $200 \mathrm{ECU}, \mathrm{s} / \mathrm{he}$ received at the start of the round, plus the revenue generated by the sum of the employee's effort and the luck factor, minus the fixed wage he/she paid, and minus the piece rate he/she paid. In other words:

Employer's Earnings $=200$ ECU $+50 \mathbf{x}($ Effort+Luck $)-$ Fixed Wage - Piece Rate $\mathbf{x}$ (Effort+Luck)

For the employee, his/her earnings are his/her $200 \mathrm{ECU}$ plus the fixed wage plus the piece rate times the sum of effort and the luck factor, minus the cost of effort. In other words:

Employee's Earnings $=200$ ECU + Fixed Wage + Piece Rate $\mathbf{x}($ Effort + luck $)-$ Cost of Effort

\section{Overview}

1. The employer chooses the fixed wage (from 50 to 200), the piece rate (5-40) and suggests an effort level (from 5 to 10 ) to the employee.

2. Afterwards, the employee has been informed of the offered contract, and he/she has to decide either to accept or reject the contract. If the employee rejects the contract, the stage finishes. If s/he accepts the contract, s/he receives the offered fixed wage and decides an effort level (from 5 to 10).

3. Once the employee has decided an effort level, the computer calculates the earnings of the employer and the employee and informs both participants.

4. This procedure is repeated until we reach round 10 . 


\section{Some examples}

Think of the following examples carefully and try to see if the earnings have been calculated correctly. The numbers chosen are purely illustrative.

\section{Example 1:}

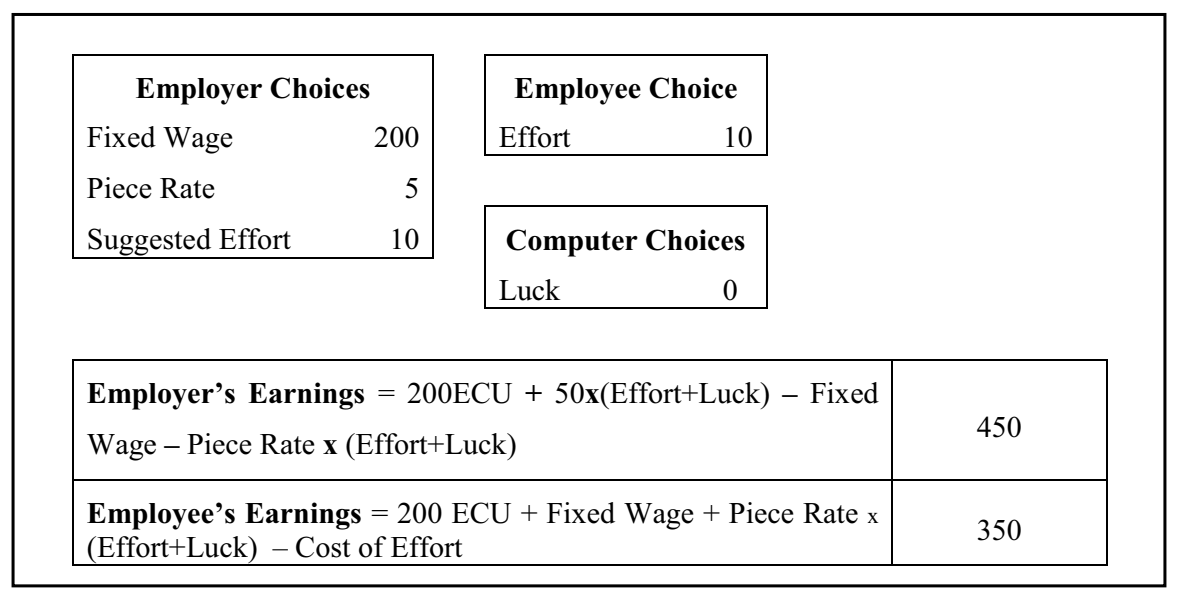

\section{Example 2:}

\begin{tabular}{|lr|}
\hline \multicolumn{2}{|c|}{ Employer Choices } \\
Fixed Wage & 200 \\
Piece Rate & 10 \\
Suggested Effort & 10 \\
\hline
\end{tabular}

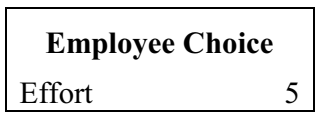

\section{Computer Choices}

Luck $\quad-2$

\begin{tabular}{|l|c|}
\hline $\begin{array}{l}\text { Employer's Earnings }=200 \mathrm{ECU}+50 \mathbf{x}(\text { Effort+Luck })-\text { Fixed } \\
\text { Wage }- \text { Piece Rate } \mathbf{x}(\text { Effort+Luck })\end{array}$ & 120 \\
\hline $\begin{array}{l}\text { Employee's Earnings }=200 \text { ECU + Fixed Wage + Piece Rate x } \\
(\text { Effort+Luck) - Cost of Effort }\end{array}$ & 405 \\
\hline
\end{tabular}




\section{Example 3:}

\begin{tabular}{|lr|}
\hline \multicolumn{2}{|c|}{ Employer Choices } \\
Fixed Wage & 50 \\
Piece Rate & 20 \\
Suggested Effort & 10 \\
\hline
\end{tabular}

\begin{tabular}{|lr|}
\hline \multicolumn{2}{|c|}{ Employee Choice } \\
Effort & 10 \\
\hline
\end{tabular}

\section{Computer Choices}

Luck

$+2$

\begin{tabular}{|l|c|}
\hline $\begin{array}{l}\text { Employer's Earnings }=200 E C U \\
\text { Wage }- \text { Piece Rate } \mathbf{x}(\text { Effort+Luck })\end{array}$ & 510 \\
\hline $\begin{array}{l}\text { Employee's Earnings }=200 \text { ECU + Fixed Wage + Piece Rate x } \\
\text { (Effort+Luck) - Cost of Effort }\end{array}$ & 390 \\
\hline
\end{tabular}

\section{Example 4:}

\begin{tabular}{|lr|lr|}
\hline \multicolumn{1}{|c|}{ Employer Choices } & & \multicolumn{2}{c|}{ Employee Choice } \\
Fixed Wage & 50 \\
Piece Rate & 30 & & \\
Effort & \\
Suggested Effort & 8 & & Computer Choices \\
\cline { 3 - 4 } & & Luck & -5 \\
\hline
\end{tabular}

\begin{tabular}{|l|c|}
\hline $\begin{array}{l}\text { Employer's Earnings }=200 \mathrm{ECU}+50 \mathbf{x}(\text { Effort+Luck })-\text { Fixed } \\
\text { Wage }- \text { Piece Rate } \mathbf{x}(\text { Effort+Luck })\end{array}$ & 250 \\
\hline $\begin{array}{l}\text { Employee's Earnings }=200 \text { ECU + Fixed Wage + Piece Rate } \mathrm{x} \\
(\text { Effort+Luck })-\text { Cost of Effort }\end{array}$ & 300 \\
\hline
\end{tabular}




\section{Example 5:}

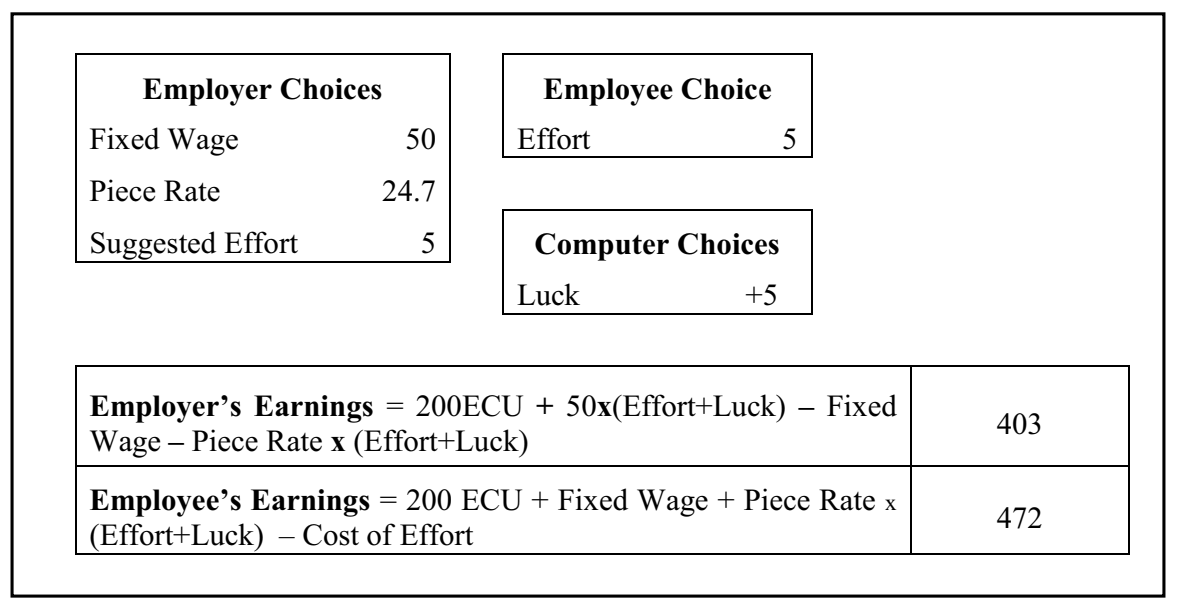

\section{References}

Anderhub, V., Gächter, S., \& Königstein, M. (2002). Efficient contracting and fair play in a simple principal-agent experiment. Experimental Economics, 5, 5-27.

Blais, A., \& Weber, E. (2006). Domain-specific risk-taking (DOSPERT) scale for adult populations. Judgement and Decision Making, 1, 33-47.

Budde, J., \& Kräkel, M. (2011). Limited liability and the risk-incentive relationship. Journal of Economics, 102(2), 97-110.

Camerer, C., \& Weber, R. (2013). Experimental organizational economics. The handbook of Organizational Economics, 2013, 213-262.

Charness, G., Frechette, G. R., \& Kagel, J. H. (2004). How robust is laboratory gift exchange?. Experimental Economics, 7(2), 189-205.

Charness, G., Gneezy, U., \& Henderson, A. (2018). Experimental methods: Measuring effort in economics experiments. Journal of Economic Behavior \& Organization, 149, 74-87.

Charness, G., \& Kuhn, P. (2010). Lab labor: What can labor economists learn from the lab? In O. Ashenfelter, \& D. Card (Ed.), Handbook of labor economics (Vol. 4, pp. 229-330). Amsterdam, NorthHolland: Elsevier.

Cooper, D. J., \& Kagel, J. H. (2003). The impact of meaningful context on strategic play in signaling games. Journal of Economic Behavior \& Organization, 50, 311-337.

Cooper, D. J., \& Kagel, J. H. (2009). The role of context and team play in cross-game learning. Journal of the European Economic Association, 7, 1101-1139.

Corgnet, B., \& Hernán-González, R. (2018). Revisiting the trade-off between risk and incentives: The shocking effect of random shocks? Management Science 65, 955-1453.

Dalal, D., \& Zickar, M. (2012). Some common myths about centering predictor variables in moderated multiple regression and polynomial regression. Organizational Research Methods, 15, 339-362.

Fehr, E., \& Gächter, S. (2002). "Do incentive contracts undermine voluntary cooperation?" Institute for Empirical Research in Economics, IEW Working Paper 34, University of Zurich.

Fehr, E., Kirchsteiger, G., \& Riedl, A. (1998). Gift exchange and reciprocity in competitive experimental markets. European Economic Review, 2921(42), 1-34.

Fehr, E., Klein, A., \& Schmidt, K. M. (2007). Fairness and contract design. Econometrica, 75(1), 121-154.

Fehr, E., \& Schmidt, K. M. (1999). A theory of fairness, competition and cooperation. Quarterly Journal of Economics, 114, 817-868. 
Fehr, E., \& Schmidt, K. M. (2004). Fairness and incentives in a multi-task principal-agent model. Scandinavian Journal of Economics, 106, 453-474.

Fehr, E., \& Schmidt, K. M. (2007). Adding a stick to the carrot? The interaction of bonuses and fines. The American Economic Review, 97, 177-181.

Fischbacher, U. (2007). z-Tree: Zurich toolbox for ready-made economic experiments. Experimental Economics, 10, 171-178.

Hart, O., \& Holmström, B. (1986). The theory of contracts. Cambridge: Mimeo.

Holmstrom, B., \& Milgrom, R. (1987). Aggregation and linearity in the provision of intertemporal incentives. Econometrica, 55, 303-328.

Holt, C., \& Laury, S. (2002). Risk aversion and incentive effects. American Economic Review, 92, 1644-1655.

Hoppe, E. I., \& Schmitz, P. W. (2015). Do sellers offer menus of contracts to separate buyer types? An experimental test of adverse selection theory. Games and Economic Behavior, 89, 17-33.

Karakostas, A., Sonntag, A., \& Zizzo, D. J. (2017). Contract choice: Efficiency and fairness in revenuesharing contracts. The Scandinavian Journal of Economics, 119(4), 962-986.

Krueger, J. (2007). From social projection to social behaviour. European Review of Social Psychology, $18,1-35$.

Milgrom, P. R., \& Roberts, J. D. (1992). Economics, organization and management. New York: Prentice Hall.

Orbell, J., \& Dawes, R. M. (1991). A “cognitive miser” theory of cooperators advantage. American Political Science Review, 85(2), 515-528.

Prendergast, C. (1999). The provision of incentives in firms. Journal of Economic Literature, 37, 7-63.

Prendergast, C. (2000). What trade-off of risk and incentives. American Economic Review AEA Papers and Proceedings, 90, 421-425.

Prendergast, C. (2002). The tenuous trade-off between risk and incentives. Journal of Political Economy, 110, 1071-1102.

Robbins, J. M., \& Krueger, J. I. (2005). Social projection to ingroups and outgroups: A review and metaanalysis. Personality and Social Psychology Review, 9(1), 32-47.

Sloof, R., \& van Praag, M. (2008). Performance measurement, expectancy and agency theory: An experimental study. Journal of Economic Behavior \& Organization, 67, 794-809.

Sloof, R., \& Van Praag, C. M. (2010). The effect of noise in a performance measure on work motivation: A real effort laboratory experiment. Labour Economics, 17(5), 751-765.

Vroom, V. H. (1964). Work and motivation (Vol. 45). New York: Wiley.

Wright, D. J. (2004). The risk and incentives trade-off in the presence of heterogeneous managers. Journal of Economics, 83(3), 209-223.

Publisher's Note Springer Nature remains neutral with regard to jurisdictional claims in published maps and institutional affiliations. 